\title{
Screening for neonatal hearing loss in the Eastern region of United Arab Emirates
}

M. Ur Rehman, ${ }^{7}$ K. Mando, ${ }^{7}$ A. Rahmani, ${ }^{1}$ A. Imran, ${ }^{7}$ N. Ur Rehman, ${ }^{7}$ K. Gowda ${ }^{2}$ and F. Chedid ${ }^{7}$

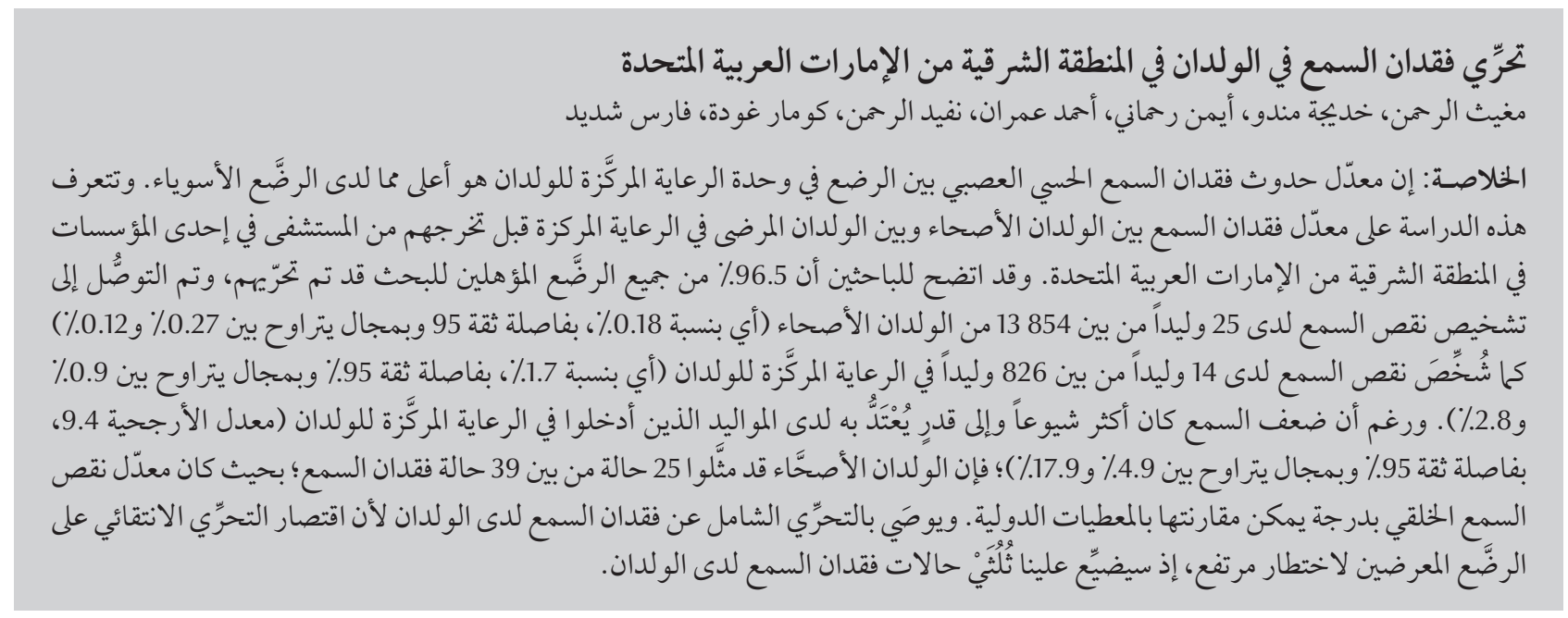

ABSTRACT The incidence of sensorineural hearing loss among infants in the neonatal intensive unit (NICU) is higher than in normal infants. This study determined the rate of hearing loss in healthy newborns and in NICU patients before hospital discharge at a single institution in the Eastern region of the United Arab Emirates; $96.5 \%$ of all eligible infants were screened. Hearing deficit was diagnosed in 25/13 854 healthy newborns $(0.18 \% ; 95 \%$ $\mathrm{Cl}: 0.12 \%-0.27 \%)$ and $14 / 826$ infants in the $\mathrm{NICU}(1.7 \% ; 95 \% \mathrm{Cl}: 0.9 \%-2.8 \%)$. Although hearing impairment was significantly more common in those admitted to the NICU ( $R R=9.4 ; 95 \% \mathrm{Cl}$ : 4.9-17.9), healthy newborns accounted for 25 of the 39 cases with hearing loss. The rate of congenital hearing deficit was comparable to international data. Universal screening is recommended since selective screening of high-risk infants missed twothirds of newborns with hearing loss.

\section{Dépistage des pertes d'audition chez le nouveau-né dans la région orientale des Émirats arabes unis}

RÉSUMÉ L'incidence d'une perte d'audition neurosensorielle chez les nouveau-nés admis au service des soins intensifs néonatals est supérieure à celle observée chez les nouveaux-nés normaux. L'étude a déterminé le taux de la perte d'audition chez des nouveau-nés en bonne santé et chez des patients du service des soins intensifs néonatals avant leur sortie d'hôpital dans un unique établissement de la région orientale des Émirats arabes unis ; 96,5\% de tous les enfants éligibles ont été dépistés. Le diagnostic d'une perte auditive a été posé chez 25 des 13854 nouveau-nés en bonne santé $(0,18 \%$; IC à $95 \%: 0,12 \%-0,27 \%)$ et chez 14 des 826 nouveau-nés hospitalisés dans le service des soins intensifs néonatals (1,7\%; IC à $95 \%$ : 0,9\%-2,8\%). Si une déficience auditive était nettement plus fréquente chez les enfants admis dans les services des soins intensifs néonatals (RR = 9,4; IC à $95 \%$ : 4,9-17,9), les nouveau-nés en bonne santé représentaient 25 des 39 cas de perte d'audition. Le taux de déficit auditif congénital était comparable aux données internationales. Le dépistage universel est recommandé car un dépistage sélectif des enfants à haut risque passe à côté des deux tiers des nouveau-nés atteints d'une perte d'auditition. 


\section{Introduction}

The prevalence of permanent hearing impairment in infants and young children ranges from $0.1 \%$ to $0.2 \%[1-3]$. The incidence of sensorineural hearing loss among infants who have been in a neonatal intensive unit (NICU) varies from $2.1 \%-17.5 \%$ depending upon the presence of different risk factors [4-6]. However lower rates have been reported $(0.7 \%-1.5 \%)$ in more recent published studies [7-9].

Even a mild and unilateral auditory deficit can lead to delay in the development of a child's speech and language. The rate of hearing loss in the United Arab Emirates (UAE) is not yet known. The hearing screening programme was introduced at Tawam Hospital in Al Ain in July 2007 for early identification of high-risk infants and intervention to avoid delays in speech and cognitive development. The present study determined the rate of hearing loss at Tawam Hospital among well newborns and infants who needed NICU care.

\section{Methods}

\section{Study design and subjects}

The results of hearing screening for consecutive healthy newborns admitted to the well-baby nursery and all newborns admitted to the NICU from 1 July 2007 to 31 December 2010 were reviewed. Babies who died or were transferred or came from other hospitals were excluded from the study.

\section{Data collection}

The screening was done prior to infants' discharge from the hospital. Measurements were done using distortion product oto-acoustic emission with the interacoustic instrument at $30-40 \mathrm{db}$. If any infant failed at $40 \mathrm{db}$ then a diagnostic auditory brainstem response test $(\mathrm{ABR})$ was used to assess the amount of hearing loss. Both tests were performed by the Vivosonic integrity ABR TM V500.

Those infants who failed the initial screening were followed at monthly intervals at the audiology clinic and the ABR was repeated to confirm the final diagnosis of hearing deficit and to plan further management. All babies who were admitted to the NICU and passed the hearing test were given an appointment after 6 months for rescreening.

\section{Statistical analysis}

The data were analysed using SPSS, version 18.0. The proportion of infants with hearing loss was reported and the 95\% confidence interval (CI) was calculated using the Poisson distribution for rare independent events. The rate of hearing loss of healthy newborns and NICU graduates were compared using the Fisher exact test. The relative risk (RR) for sensorineural hearing loss was calculated.

\section{Results}

Between 1 July 2007 and 31 December 2010, 13854 healthy infants and 856 from the NICU were screened, which was $96.5 \%$ of all infants eligible for hearing screening. Of these, 25 infants (0.18\%; 95\% CI: 0.12\%-0.27\%) from the well-baby nursery and 14 (1.7\%; 95\% CI: $0.9 \%-2.8 \%$ ) from the NICU had confirmed sensorineural hearing loss. The rate of hearing screening in the NICU cases was significantly higher than healthy infants $(\mathrm{RR}=9.4 ; 95 \%$ CI: 4.9-17.9) $(P<0.001)$, although $25 / 39(64.1 \%)$ of the cases of hearing loss were identified among infants at the well-baby nursery.

\section{Discussion}

It is very important to identify infants with a hearing impairment within an appropriate period of time [10]. Definite diagnosis for hearing impairment within the first 6 months of life increases the possibility of appropriate speech and language development and reduces neurodevelopmental problems [11]. The hearing screening programme was started at Tawam hospital in Al Ain Emirate in July 2007 with the aim of identifying the rate of hearing loss among well newborns and high-risk infants who needed NICU care. Recently, it was included in the expanded neonatal screening in $\mathrm{Abu}$ Dhabi Emirate [12].

The rate of sensorineural hearing loss among well infants at our hospital $(0.18 \%)$ was very similar to reported incidences from Saudi Arabia (0.18\%) [13] and Oman (0.12\%) [14] but was considerably lower than in Kuwait (2.0\%) and Jordan (1.37\%) [7]. The international figures for hearing deficit among well babies has been reported to range between $0.1 \%$ and $0.2 \%[1-3]$.

The rate of hearing loss among high-risk infants admitted to our NICU (1.7\%) was also comparable to the international data $(0.7 \%-1.5 \%)$ $[8,9]$, and well below the reported results from Saudi Arabia (13.5\%) [13]. Al Kandari and Alshuaib from Kuwait reported a very high rate of hearing loss of $46.6 \%$ in NICU patients [7], but the sample size was very small $(n=15)$. The implementation of a preventive strategy, including noise control, infection preventive strategies and routine measurement of serum aminoglycoside concentration and close monitoring of oxygen supplementation might partly explain the lower rate of hearing loss in our population. In spite of concerted efforts to minimize the exposure to known risk factors, hearing loss in our NICU patients remained 10 times higher than in healthy newborns. Limiting the screening to NICU patients would have failed to detect twothirds of patients affected with hearing loss in our study population. Infants who pass newborn hearing screening 
at discharge from NICU should be rescreened after 24 to 36 months to diagnose delayed onset hearing loss $[8,15]$.

The coverage of our hearing screening programme (96.5\%) could be improved by checking the hearing screening results of all babies at the time of discharge and first neonatal follow-up visit.

\section{Conclusion}

This study from the UAE reveals a rate of hearing deficit comparable to other Gulf countries and illustrates the importance of implementing universal hearing screening programme in both healthy neonates and high-risk newborns admitted to the NICU. Limiting the screening to the high-risk group would fail to identify healthy newborns with hearing deficit, which accounts for two-third of cases in our study.

\section{Acknowledgements}

We thank Hachem Jammal and Celine Chedid for their contribution in collecting the data and reviewing the manuscript.

\section{References}

1. Berg AL et al. Newborn hearing screening in the NICU: profile of failed auditory brainstem response/passed otoacoustic emission. Pediatrics, 2005, 116:933-938.

2. Joint Committee on infant Hearing, American Academy of Pediatrics. Year 2007 position statement: principles and guidelines for early hearing detection and intervention programs. Pediatrics, 2007, 120:989-291.

3. Cone-Wesson B et al. Identification of neonatal hearing impairment: infants with hearing loss. Ear and Hearing, 2000, 21:488-507.

4. Abramovich SJ et al. Hearing loss in very low birthweight infants treated with neonatal intensive care. Archives of Disease in Childhood, 1979, 54:421-426.

5. Bergman I et al. Cause of hearing loss in the high-risk premature infant. Journal of Pediatrics, 1985, 106:95-101.

6. Bradford BC et al. Identification of sensory neural hearing loss in very preterm infants by brainstem auditory evoked potentials. Archives of Disease in Childhood, 1985, 60:105-109.

7. Al-Kandari JM, Alshuaib WB. Newborn hearing screening in Kuwait. Electromyography and Clinical Neurophysiology, 2007, 47:305-313.

8. Cristobal R, Oghalai JS. Hearing loss in children with very low birth weight: current review of epidemiology and pathophsiology. Archives of Disease in Childhood. Fetal and Neonatal Edition, 2008, 93:462-468.
9. Oghalai JS et al. Neonatal hearing loss in the indigent. Laryngoscope, 2002, 112:281-286.

10. Yoshikawa $S$ et al. The effects of hypoxia, premature birth, infection, ototoxic drugs, circulatory system and congenital disease on neonatal hearing loss. Larynx, 2004, 31:361-368.

11. Wroblewska-Seniuk $\mathrm{K}$ et al. The results of newborn hearing screening by means of transient evoked otoacoustic emissions. International Journal of Pediatric Otorhinolaryngology, 2005, 69:1351-1357.

12. Abu Dhabi newborn screening program. Health professional manual. Abu Dhabi, Abu Dhabi Health Authority, 2009:29-31.

13. Habib HS, Abdelgaffar $\mathrm{H}$. Neonatal hearing screening with transient evoked otoacoustic emissions in Western Saudi Arabia. International Journal of Pediatric Otorhinolaryngology, 2005, 69:839-842.

14. Khandekar R et al. Neonatal screening for hearing impairment-the Oman experience. International Journal of Pediatric Otorhinolaryngology, 2006, 70:663-670.

15. Johnson JL et al. A multicenter evaluation of how many infants with permanent hearing loss pass a two-stage otoacoustic emissions/automated auditory brainstem response newborn hearing screening protocol. Pediatrics, 2005, 116:663-672. 